\title{
Longterm treatment of irritable bowel syndrome with cimetropium bromide: a double blind placebo controlled clinical trial
}

\author{
G Dobrilla, B P Imbimbo, L Piazzi, G Bensi
}

\begin{abstract}
The aim of this study was to evaluate the efficacy of cimetropium bromide, a new antimuscarinic compound, in relieving symptoms of patients with irritable bowel syndrome over a three month period. Seventy consecutive outpatients were given cimetropium (50 mg tid) or placebo according to a double blind, randomised, parallel groups design. Symptoms were evaluated initially and at monthly intervals up to the end of the study period. One patient receiving placebo withdrew because of treatment failure. Pain score decreased by $\mathbf{4 0}$, $66,85 \%$ in the cimetropium group, at the end of the first, second and third months respectively, compared with 26,32 and $52 \%$ reductions among controls $(p=0.0005)$. At the end of treatment there was a $86 \%$ reduction in the number of abdominal pain episodes per day in the cimetropium group compared with $50 \%$ in the placebo group $(\mathbf{p}=\mathbf{0} \cdot 001)$. Constipation and diarrhoea scores decreased by 59 and $49 \%$ in the cimetropium treated patients, compared with 37 and $39 \%$ in controls, the differences between being not significant. At the end of the study $89 \%$ of the patients treated with cimetropium considered themselves as globally improved as opposed to $69 \%$ in the placebo group $(p=0.039)$. The corresponding $95 \%$ confidence intervals for the differences between the proportion of improved patients in the two groups were from $11 \%$ to $29 \%$. Six patients taking cimetropium complained of slight dry mouth. The results of this study showed that cimetropium bromide is effective in relieving pain in patients with irritable bowel syndrome.
\end{abstract}

Despite its favourable prognosis, irritable bowel syndrome (IBS) is a social problem and up to $20 \%$ of the population are affected.' Half of the patients referred to gastroenterologists have irritable bowel syndrome. ${ }^{2}$

Anticholinergics, antispasmodics, laxatives, and bulking agents, have all been used but no benefits have been clearly shown. ${ }^{34}$ Many studies, aimed at proving drug efficacy, have failed mainly because of the good response to placebo shown by these patients: placebo response rates were sometimes over $70 \% .^{5-7}$ The placebo effects, however, tend to decrease with time ${ }^{8}$ so that the duration of the study treatment is crucial for a correct evaluation of the efficacy of any drug. Most studies were too short to produce good results. ${ }^{9}$

A critical review of a large number of trials in irritable bowel syndrome was recently published ${ }^{10}$ concluding that not a single study of the many reviewed could offer convincing evidence in favour of the efficacy of any therapy tested in treating irritable bowel syndrome.

Cimetropium bromide is a new antispasmodic agent selectively acting on the gut by antagonising acetylcholine at the smooth muscle muscarinic receptors. " 12 Unlike other antimuscarinics it has minimal effects on vascular receptors, so it has no appreciable untoward effects. ${ }^{13}$

The aim of this study was to assess the efficacy of cimetropium bromide in improving the symptoms of irritable bowel syndrome over three months - a longer period than usual.

\section{Methods}

PATIENTS

This trial was a double blind, randomised, placebo controlled, parallel groups study. It included a two week screening period and a three month test period, during which each patient was randomly assigned to drug or placebo.

Irritable bowel syndrome was diagnosed after all other organic causes for the symptoms had been excluded by the results of complete clinical examinations (including rectosigmoidoscopy and double contrast enemas) and the usual laboratory tests (erythrocyte sedimentation rate, complete blood count, serum transaminases, alkaline phosphatase, cholesterol, plasma proteins, electrophoresis, plasma urea, electrolytes, calcium, thyroid tests, urinalaysis, stool examination for occult blood, ova and parasites and stool culture, lactase intolerance). When appropriate, such additional investigations as upper abdominal ultrasonography, total colonoscopy, and oesophagogastroduodenoscopy were performed and showed nothing abnormal.

Only patients with bowel alterations and episodes of abdominal pain, usually cramp like and in lower abdominal quadrants, lasting for at least two months, were considered eligible for the study. Between October 1984 and April 1986 128 patients referred to our outpatient department were diagnosed as having irritable bowel syndrome. Of these, 89 patients conformed to the inclusion criteria; of these, 12 patients were excluded because they did not give informed

TABLE I Scores for severity of abdominal pain and abdominal distension

\section{$0=$ absent}

$\mathbf{l}=$ mild (symptom cannot be ignored, but does not influence daily activities)

$2=$ moderate (symptom influences concentration on daily activities) $3=$ severe (symptom markedly influences daily activities except the most elementary) 
consent and seven who were uncooperative or unreliable. The remaining 70 patients were randomly assigned to either the drug group or the placebo group.

During the baseline screening phase, patients received a diary card and were instructed to record the number of abdominal painful episodes and the severity of abdominal pain, abdominal distension, constipation, and diarrhoea. Diarrhoea was defined as loose to liquid stools more frequent than three times per day, constipation was considered as straining with harder stools less frequent than three times per week. Because the patients' descriptions of frequency of defaecation are unreliable, ${ }^{14}$ however, severity of constipation and diarrhoea was arbitrarily scored, taking into account subjective discomfort, on a four point scale: $0=$ none, $1=$ mild, $2=$ moderate, $3=$ severe. Severity of pain and abdominal distension was scored as shown in Table I. The attending physician recorded patients' evaluations of their symptoms and made a physical examination of the abdomen to assess the presence of pain on palpation, and contracted colon. This baseline period was also regarded as a washout phase from any drug interference with symptoms of irritable bowel syndrome.

At the end of the baseline period patients admitted to the study were randomly allocated to receive cimetropium bromide $50 \mathrm{mg}$ tablets tid or placebo tablets tid before meals for three months. No other drugs were allowed during this treatment period.

During the treatment period patients continued to record symptoms and came for monthly checkups. At these visits they handed in their diaries and were given new ones. Median scores for severity of symptoms during the previous treatment week were recorded by the attending physician and considered for statistical analysis. New treatment tablets were dispensed and unused tablets were returned and counted; another physical examination was done to check pain on palpation and presence of contracted colon.

At the end of the treatment period patients attended the final visit during which a retrospective overall assessment since the baseline visit (better, same, worse) was recorded.

The study was conducted according to the Declaration of Helsinki.

\section{STATISTICAL ANALYSIS}

Symptom scores and the number of daily painful episodes were compared within groups by the Friedman test, and between groups by the Mann-Whitney U-test. Percentage differences between these variables at baseline and monthly visits were calculated from mean values for the treatment groups. Presence or absence of pain on palpation and contracted colon were compared by Fisher's exact test. Overall assessment of treatment were compared by the $\chi^{2}$ test. The $95 \%$ confidence intervals for differences between the proportion of improved patients in the two groups and standard errors of proportions were calculated according to standard procedures. ${ }^{15}$ Values of p equal to or less than 0.05 (two-sided) were considered significant. Data were expressed as means (SEM). All calculations were made
TABLE II Characteristics of the patients

\begin{tabular}{|c|c|c|c|}
\hline & Placebo & Cimetropium & $p$ \\
\hline \multicolumn{3}{|l|}{ Sex } & NS \\
\hline Age (yrs) & & & \\
\hline $\begin{array}{l}\text { median } \\
\text { range }\end{array}$ & $\begin{array}{l}45 \\
22-63\end{array}$ & $\begin{array}{l}45 \\
24-67\end{array}$ & NS \\
\hline \multicolumn{4}{|l|}{ Duration of disease (yrs) } \\
\hline $\begin{array}{l}\text { median } \\
\text { range }\end{array}$ & $\begin{array}{l}3 \cdot 0 \\
0 \cdot 2-15 \cdot 0\end{array}$ & $\begin{array}{l}3 \cdot 0 \\
0 \cdot 4-20 \cdot 0\end{array}$ & NS \\
\hline $\begin{array}{l}\text { Previous treatments } \\
\text { (yes/no) }\end{array}$ & $15 / 20$ & $16 / 19$ & NS \\
\hline \multicolumn{4}{|l|}{ Bowel habits } \\
\hline constipation & 12 & 14 & \\
\hline $\begin{array}{l}\text { diarrhoea } \\
\text { alternating const/diarr }\end{array}$ & $\begin{array}{r}12 \\
9\end{array}$ & $\begin{array}{r}13 \\
8\end{array}$ & NS \\
\hline \multicolumn{4}{|l|}{ Habits } \\
\hline smoking (yes/no) & $14 / 21$ & $11 / 24$ & NS \\
\hline alcohol (yes/no) & $18 / 17$ & $18 / 17$ & NS \\
\hline coffee (yes/no) & $34 / 1$ & $30 / 5$ & NS \\
\hline fibres (yes/no) & $4 / 31$ & $5 / 30$ & NS \\
\hline laxative (yes/no) & $6 / 29$ & $7 / 28$ & NS \\
\hline
\end{tabular}

with the NWA STATPAK statistical package. ${ }^{16}$

\section{Results}

One patient in the placebo group withdrew from the study because of treatment failure. He was included in the analysis according to the intention to treat approach. Patients in the placebo group returned $8.9(1 \cdot 3) \%$ of the assigned treatment tablets, while patients on cimetropium returned $8 \cdot 2(0.8) \%$ of given tablets.

The patients in the two treatment groups were comparable as regards their personal data and medical history (Table II).

\section{SYMPTOMS}

Figures 1 and 2 show frequency and severity of abdominal pain of the two groups during treatment. In the placebo group the number of painful episodes per day dropped during the first month, but did not improve further significantly. The percentage decreases were 35,43 , and $50 \%$ respectively at the first, second and third month

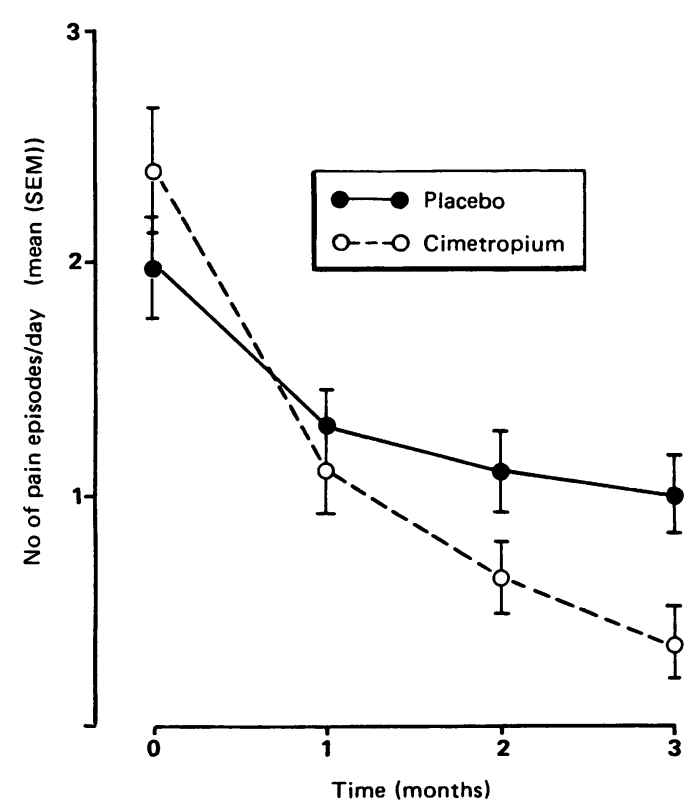

Figure 1: Mean numbers of pain episodes per day for the placebo and the cimetropium groups during the three months of treatment. 


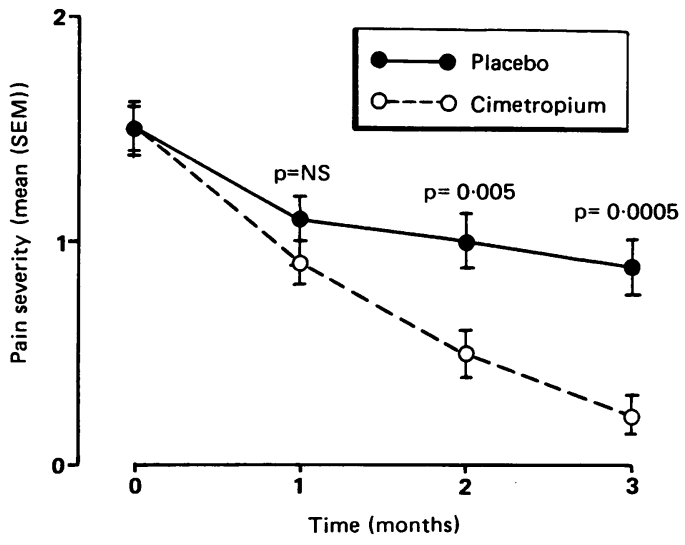

Figure 2: Abdominal pain severity for the placebo and the cimetropium groups during the three months of treatment.

of therapy. A similar trend was observed for severity of pain $(26,32$ and $52 \%$ decreases)

In cimetropium treated patients, severity and frequency of abdominal pain constantly decreased throughout the three months of treatment. Monthly decreases were 54,73 , and $86 \%$ for frequency and $40,66,85 \%$ for severity of abdominal pain. At the end of treatment, improvement of pain in the cimetropium group was significantly greater than in the placebo group both for frequency $(\mathrm{p}=0.001)$ and severity $(\mathrm{p}=0.0005)$.

At the end of treatment, severity of abdominal distension decreased by an average of $82 \%$ in the cimetropium group and $54 \%$ in the placebo group ( $\mathrm{p}=0.055$, Fig 3 ).

Scores for severity of constipation and diarrhoea decreased by 59 and $49 \%$ in cimetropium treated patients and by 37 and $39 \%$ in placebo treated patients, the differences between treatment groups being not significant.

\section{PHYSICAL EXAMINATION}

At the pretreatment visit $54(8) \%$ of patients in the placebo group and $34(8) \%$ of patients in the cimetropium group complained of pain on palpation. At the end of the study 17 (6)\% of patients on placebo still presented pain on palpation while none of the patients given active drug complained of this ( $p=0 \cdot 012$, Fig 4$)$.

Evidence of contracted colon was found in 60 (8)\% of patients in the cimetropium group at the
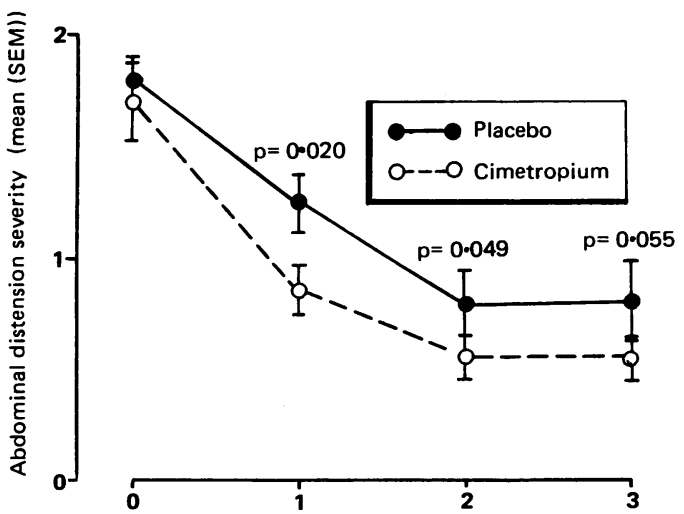

Figure 3: Abdominal distension severity for the placebo and the cimetropium groups during the three months of treatment.

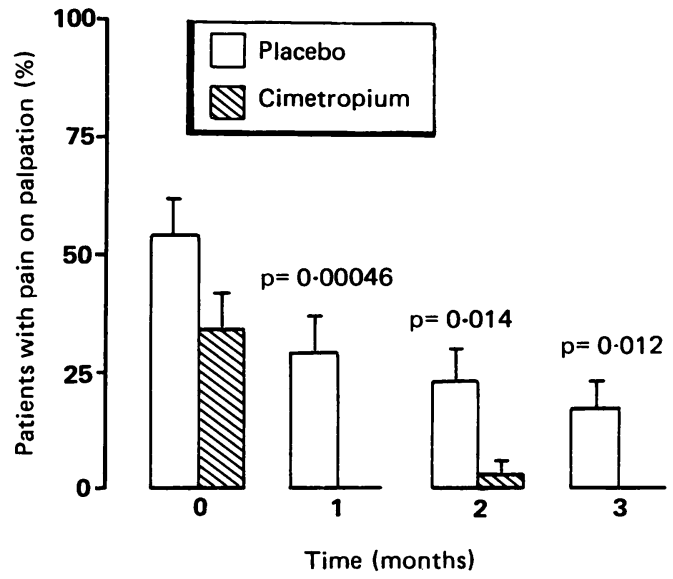

Figure 4: Percentage of patients with pain on palpation in the placebo and the cimetropium group during the three months of treatment.

beginning of the study and in $14(6) \%$ at the final visit, compared with $63(8) \%$ in the placebo group at the beginning, and $43(8) \%$ at the end $(p=0.008$, Fig 5$)$.

OVERALL ASSESSMENT OF THE TREATMENT At the end of the study $89 \%$ of the patients treated with cimetropium considered themselves improved while only $69 \%$ of the placebo treated patients showed similar results, the difference between the two groups being significant $(p=$ 0.039 ). The $95 \%$ confidence interval for the differences between the improvements in the two groups was 11 to $29 \%$.

\section{LABORATORY TESTS}

Blood and urine tests were done before and at the end of treatment. No patient showed significant differences in laboratory values compared with initial results, in either the drug or the placebo group.

\section{UNTOWARD EFFECTS}

In the cimetropium group, six patients complained of dry mouth. This effect is considered to be a typical anticholinergic manifestation of the

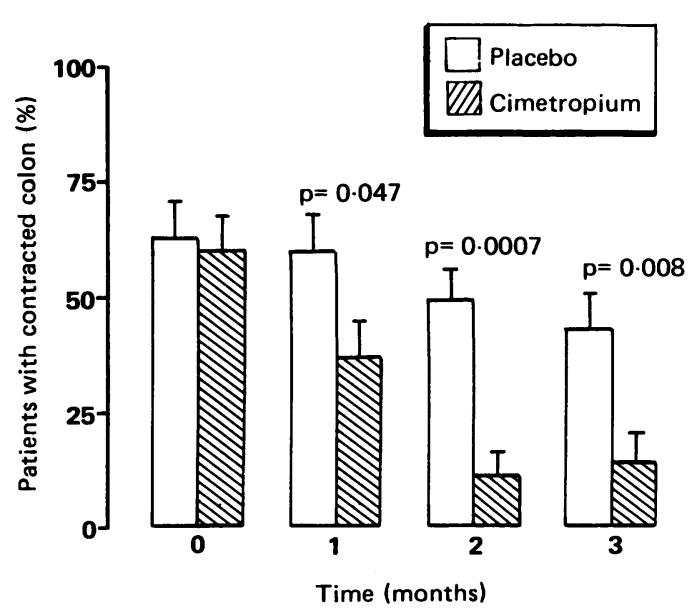

Figure 5: Percentage of patients with contracted colon in the placebo and the cimetropium group during the three month of treatment. 
drug. One patient taking placebo reported insomnia. None of the six drug treated patients reporting dry mouth withdrew from the study or required dosage reduction.

\section{Discussion}

Because of the lack of any real objective marker for assessing improvement in irritable bowel syndrome, and taking into account the frequent very large placebo response during the first month of therapy, a randomised, double blind, placebo controlled trial, for at least eight weeks ${ }^{10}$ has been recently considered the only method for reliably assessing irritable bowel syndrome therapies. The present study showed up the efficacy of cimetropium in improving symptoms of irritable bowel patients over a three month period, although the lower limit $(11 \%)$ of the $95 \%$ confidence interval of the difference between the percentages of patients improving on placebo and cimetropium, is of limited clinical significance.

The results regarding abdominal pain showed that the decrease in frequency and intensity continued throughout the whole treatment period in the cimetropium group while no further significant improvement was seen in the placebo group after the first month of treatment. This is in agreement with the loss of placebo effects on irritable bowel symptoms during long lasting therapy. ${ }^{8}$ The choice of a three month treatment period, enough to overcome the bias of the placebo effect, enabled us to detect a significant difference between the two groups. Pain on palpation and presence of contracted colon were also significantly relieved in the cimetropium group, compared with controls. Difference in improvement of abdominal distension between the two treatment groups reached a border line significant level $(p=0.055)$ at the end of treatment. Bowel habits showed greater improvement in the cimetropium group than in the placebo group, although not enough to reach a significant level. This is probably due to the fact that these symptoms are generally of slight intensity and very changeable. Some of the patients had periods of constipation alternating to diarrhoea. Compared with placebo, however, cimetropium improved more constipation than diarrhoea and this is in accordance with classic literature that justify the use of anticholinergic agents in 'spastic colon' but not for 'nervous diarrhoea'. ${ }^{17}$ Cimetropium bromide, given orally for one month, was recently proved to accelerate intestinal transit time in irritable bowel syndrome patients with abdominal pain and constipation. ${ }^{18}$ Although only 1 to $4 \%$ of the administered dose is absorbed, ${ }^{19}$ the drug nevertheless reaches effective concentrations after repeated ora doses $^{20}$ because of significant accumulation because of its long terminal half life ( 29 hours). When given intravenously at the dose of 5 and 10 $\mathrm{mg}$, cimetropium bromide was effective in reducing the motor responses to a meal in the transverse and sigmoid colon of healthy subjects ${ }^{21}$ and in the sigmoid colon of patients with irritable bowel syndrome. ${ }^{22}$

Six patients on cimetropium complained of dry mouth, a typical anticholinergic side effect. Patients taking anticholinergics who recognise side effects may come to recognise whether they are taking an active drug or placebo. This is a general problem in all placebo controlled trials with patients who are familiar with the possible side effects of the active drug.

In conclusion, the proper design and suitable duration of this study, together with the adequate size of the two groups investigated, confirms the results of previous smaller placebo controlled clinical trials ${ }^{232+}$ on the efficacy of cimetropium bromide in the treatment of irritable bowel syndrome.

1 Drossman DA, Sandler RS, McKee DC, et al. Bowel dysfunction among subjects not seeking health care. Gastroenterology 1982; 83: 529-34.

2 Thompson WG. Irritable bowel syndrome: prevalence, prognosis and consequences. Can Med Assoc $\mathcal{f}$ 1986; 134: 111-3.

3 Drossman DA. Lowman BC. Irritable bowel syndrome: epidemiology, diagnosis and treatment. Clin Gastroenterol 1985; 14: 559-73.

4 Drug and therapeutic bulletin. Vol 24. London: 1 December $1986 ; 24: 93-5$.

5 Fielding JF. Timolol treatment in the irritable bowel syndrome. Digestion 1981; 22: 155-8.

6 Longstreth GF, Fox DD, Youkeles L, et al. Psyllium therapy in the irritable bowel syndrome: a double blind trial. An Intern Med 1981; 95: 53-6.

7 Fielding JF. Domperidone treatment in the irritable bowe syndrome. Digestion 1982; 23: 125-7.

8 Ritchie JA, Truelove SC. Treatment of irritable bowel syndrome with lorazepam, hyoscine butylbromide and isphaghula husk. BrMed F 1979; 1: 376-8.

9 Prout BJ. The treatment of irritable bowel syndrome. Practitioner 1983; 227: 1607-8.

$10 \mathrm{Klein}$ KB. Controlled treatment trials in the irritable bowe syndrome: a critique. Gastroenterology 1988; 95: 232-41.

11 Schiavone A, Schiavi GB, De Conti L, et al. Cimetropium characterization of antimuscarinic and spasmolytic properties. Arzneimforsch Drug Res 1985; 35: 796-9.

12 Sagrada A, Schiavone A, Cefalà A, et al. Cimetropium bromide: in vitro and in vivo evaluation of spasmolytic activity on human and dog colon. Digestion 1989; 42: 143-50.

13 Litta Modigniani R, Mazzolari M, Berantani E, et al. Relative potency of the atropine-like effects of a new parasympatholytic drug, scopolamine $\mathrm{N}$-(cyclopropylmethyl) bromide and those of hyoscine N-butyl bromide. Curr Med Res Opin 1978; 5: 333-40.

14 Oettle GJ, Heaton $\mathrm{KW}$ Is there a relationship between symptoms of the irritable bowel syndrome and objective mymptoms of the irritable bowel syndrome and objective measurements of large bow

15 Gardner MJ, Altman D. Confidence intervals rather than $P$ values: estimation rather than hypothesis testing. $\mathrm{Br} \mathrm{Med} \mathcal{f}$ 1986; 292: 746-50.

16 NWA STATPAK multi-function statistic library, version 3.1. Northwest Analytical Inc, Portland, Oregon, 1984

17 Ivey KJ. Are anticholinergics of use in the irritable colon syndrome? Gastroenterology 1975; 68: 1300-7.

18 Passaretti S, Guslandi M, Imbimbo BP, et al. Effects of cimetropium bromide on gastrointestinal transit-time in patients with irritable bowel syndrome. Alim Pharm Ther patients with irtit

19 Imbimbo BP, Daniotti S, Vidi A, et al. Discontinuous ora absorption of cimetropium bromide, a new antispasmodic absorption of cimetropium bromide,

20 Imbimbo BP, Piperno A, Fiorelli G, et al. Urinary excretion of cimetropium bromide after multiple oral doses. Eur $\mathcal{F}$ Clin Pharmacol 1987; 33: 337-8.

21 Bassotti G, Imbimbo BP, Gaburri M, et al. Transverse and sigmoid colon motility in healthy humans: effect of eatin and of cimetropium bromide. Digestion 1987; 36: 59-64.

22 Lanfranchi GA, Bazzocchi G, Campieri M, et al. Cimetropium bromide reduces the colonic motor response to eating in patients with the irritable bowel syndrome. Eur $\mathcal{J}$ Clin Pharmacol 1988; 33: 571-5.

23 Piai G, Visconti M, Imbimbo BP, et al. Long-term treatmen of irritable bowel syndrome with cimetropium bromide, a new antimuscrinic compound. Curr Ther Res 1987; 41: 96777.

24 Centonze V, Imbimbo BP, Campanozzi F, et al. Oral cimetropium bromide, a new antimuscarinic drug, for long-term treatment of irritable bowel syndrome. Am $\mathcal{f}$ Gastroenterol 1988; 83: 1262-6. 